\title{
Factors Influencing Motor Outcome of Hippotherapy in Children with Cerebral Palsy
}

\author{
Yeo Seung $\mathrm{Mi}^{1}$ Lee ji Young ${ }^{2}$ Shin Hye Yeon ${ }^{2}$ Seo Yun Sik ${ }^{2} \quad$ Kwon Jeong $\mathrm{Yi}^{1}$ \\ ${ }^{1}$ Department of Physical and Rehabilitation Medicine, Samsung \\ Medical Center, Sungkyunkwan University School of Medicine, \\ Seoul, Republic of Korea \\ 2 Samsung Equestrian Team, Bugok dong, Gunposi, Gyeonggido, \\ Republic of Korea

\begin{abstract}
Address for correspondence Kwon Jeong Yi, MD, PhD, Department of Physical and Rehabilitation Medicine, Samsung Medical Center, Sungkyunkwan University School of Medicine, 81 Irwon-ro, Gangnamgu, Seoul 06351, Korea (e-mail: jeongyi.kwon@samsung.com).
\end{abstract}

Neuropediatrics 2019;50:170-177.

\begin{abstract}
Keywords

- hippotherapy

- gross motor function

- cerebral palsy

Objective This study was aimed to identify individual factors influencing the gross motor outcome of hippotherapy in children with cerebral palsy (CP).

Methods One hundred and forty-six children with CP (mean age: $5.78 \pm 1.72$ years, male: $56.2 \%$ ) presenting variable function (gross motor function classification system [GMFCS], levels I-IV) participated in this study. Participants received 30 minutes of hippotherapy twice a week for 8 weeks. Clinical information including GMFCS level, age, sex, CP distribution, CP type, gross motor function measure-88 (GMFM-88), GMFM-66, and pediatric balance scale (PBS) score were collected retrospectively. We regarded the children with GMFM- 66 score increased by 2.0 points as good responders to hippotherapy. Further we analyzed factors affecting good responders.

Results GMFCS level I and II compared with IV (odds ratio [OR] = 6.83) and III compared with IV $(O R=4.45)$ were significantly associated with a good response to hippotherapy. Higher baseline GMFM E $(O R=1.05)$ and lower baseline GMFM B $(O R=0.93)$ were also significantly associated with a good response to hippotherapy. Sex, age, CP type, and distribution were not factors influencing gross motor outcome of hippotherapy.

Conclusions The children with CP, GMFCS level I-III, with relatively poor postural control in sitting might have a greater chance to improve their GMFM-66 scores through hippotherapy. This supports the hypothesis that hippotherapy is a contextfocused therapy to improve postural control in sitting.
\end{abstract}

\section{Introduction}

Cerebral palsy (CP), a neurological disorder caused by nonprogressive and permanent brain damage, can result in impairments of movement, posture, sensation, perception, cognition, and motor control. Physical therapy (PT) is a common intervention for children with $\mathrm{CP}$ to practice functional movements, improve motor control, reduce impairments, and learn strategies that compensate for lost function. ${ }^{1}$

The World Health Organization's International Classification of Functioning, Disability and Health: Child and Youth

received

December 2, 2018

accepted after revision

February 23, 2019

published online

April 22, 2019

Version (ICF-CY) framework is based on a biopsychosocial model that covers functioning and disability with its components, namely, body structure, body functions, activities, and participation, and identifies the need to consider, represented by personal and environmental factors. The ICF-CY defines activity as "the execution of a task or action by an individual" and participation as "involvement in a life situation." ${ }^{2}$ Diverse evidence indicates that physical activity has a beneficial effect on all children, including children with disabilities. ${ }^{3}$ Children with $\mathrm{CP}$ participate in leisure-time physical activities less often, with less intensity and reduced diversity than their

(c) 2019 Georg Thieme Verlag KG Stuttgart · New York
DOI https://doi.org/ 10.1055/s-0039-1685526. ISSN 0174-304X. 
peers without disabilities. ${ }^{4,5}$ Reduced activity and participation cause deterioration in body function and structure, such as cardiovascular disease risk, bone density, metabolic disturbance risk, obesity, and elevated blood pressures in children with $\mathrm{CP}{ }^{6}$ However, many traditional physical therapies for children with $\mathrm{CP}$ focus on impairments within the child at the domain of body function and structure. Damiano ${ }^{7}$ stated that "treatments cannot be justified unless they produce a change in activity, participation, or, more elusively, health-related quality of life for the person receiving the intervention." Furthermore, she stated that hippotherapy for muscle symmetry and activities is regarded as a "good" treatment approach for children with CP.

Equine-assisted activities and therapies (EAATs) have been widely used as leisure activities for children with $\mathrm{CP}$ since the 1960 s. $^{8}$ Hippotherapy was developed to maximize the therapeutic effect of EAATs. The term hippotherapy refers to how occupational therapy, physical therapy, and speechlanguage pathology for professionals use evidence-based practice, and clinical reasoning in the purposeful manipulation of equine movement to engage sensory, neuromotor, and cognitive systems to achieve functional outcomes. The three-dimensional smooth, rhythmic, and repetitive movements of the walking horse produce normalized pelvic movement similar to the pelvic movement during ambulation. ${ }^{9}$ The warmth and rhythmic movement of the horse are estimated to decrease hypertonicity and increase range of motion. While adjusting the dynamic base of support from the horse, children can improve trunk strength, balance, and motor planning. ${ }^{10}$ Most importantly, children with $\mathrm{CP}$ recognize EAATs as pleasant activities rather than therapies. Children with $\mathrm{CP}$, like other children, want to be physically active, have fun, and enjoy the sensation of speed. ${ }^{11}$

EAATs have been shown to improve gross motor function, postural control, balance, ${ }^{10,12}$ gait, ${ }^{13}$ and functional performance $^{14}$ in children with CP. Several meta-analyses and systematic reviews have shown that EAATs positively affect gross motor function in children with $\mathrm{CP} .{ }^{10,12,15}$ Gross motor function measure (GMFM) is the most widely used outcome measure for assessing changes in gross motor function over time in children with CP. Although many studies have reported significant improvements in GMFM scores, a recent meta-analysis showed a nonsignificant increase in GMFM scores after EAATs in children with $\mathrm{CP} .{ }^{16}$ In fact, the improvement in the GMFM score varies widely among individuals. However, little research has been conducted on the factors that influence the gross motor outcome of EAATs in children with CP. Therefore, this study aimed to identify the individual factors influencing gross motor outcome in children with CP after hippotherapy.

\section{Methods}

\section{Study Design}

This was a retrospective study investigating children with $\mathrm{CP}$ who participated in 8 weeks of a hippotherapy program (30 minutes per session, twice a week, for a total of 16 sessions) at one local riding arena, between October 2009 and August 2016. Clinical information, including GMFCS (gross motor function classification system) level, age, sex, CP distribution, CP type, gross motor function measure- 88 (GMFM-88), GMFM-66, ${ }^{17}$ and pediatric balance scale (PBS) were collected retrospectively. GMFM-88, GMFM-66, and PBS have been used to measure the functional outcomes in participants after hippotherapy since 2009 for quality control. Since a clinically meaningful improvement in GMFM-66 was reported to be an average of $1.58,{ }^{18}$ we regarded children with an increase in GMFM-66 of 2.0 points as good responders to hippotherapy. Furthermore, we analyzed factors that affected good responders.

\section{Participants}

All participants voluntarily received hippotherapy, in addition to the conventional physiotherapy that they had participated in. All participants were screened and evaluated before and after the hippotherapy by one pediatric physiatrist who had worked at a tertiary medical center located in the Seoul metropolitan. Furthermore, the medical records of all patients were reviewed by the same physiatrist. The inclusion criteria were: (1) diagnosis of CP, (2) body weight $<35 \mathrm{~kg}$, and (3) age, 3 to 10 years. The exclusion criteria were: (1) botulinum toxin injection within 6 months, (2) selective dorsal rhizotomy or orthopedic surgery within 1 year, (3) moderate to severe intellectual disability (when the participant could not follow the one-step obey command), (4) uncontrolled seizure, and (5) poor visual or hearing acuity. These criteria have been used for selecting participants in our center since 2008. Participants who were absent for the lessons more than four times were excluded from the final analysis. All the parents agreed on behalf of the participants to refrain from botulinum toxin injection during the course of the therapy.

\section{Hippotherapy}

Samsung's Riding for the Disabled Program (RD-Samsung) in an $18 \times 27 \mathrm{~m}$ indoor riding arena located in Gunpo, Kyunggido, Republic of Korea provided hippotherapy classes. Sessions were conducted by two physical therapists who held hippotherapy clinical specialist certificates. For safety, two volunteer side walkers walked with the horse and all participants wore helmets. A soft saddle made of wool was used to maximize contact between the participants and the pony. The four ponies were trained by the staff to participate in hippotherapy (average height, $135 \mathrm{~cm}$; average weight, 294 $\mathrm{kg}$ ). The ponies and participants were matched for size and function as much as possible. Two participants were grouped together for each session, and each was assigned a separate therapist for private lessons. Our hippotherapy treatment protocol was based on the study by McGibbon et al ${ }^{19}$ which included muscle relaxation; sustenance of optimal postural alignment of the head, trunk, and lower extremities and independent sitting; and active exercises (stretching, strengthening, dynamic balance, and postural control) directed by the therapist. The participants were encouraged to maintain postural alignment during all the activities. The intensity of the exercises and degree of assistance were individualized according to the participants' ability to control their posture. 


\section{Ethics}

The study protocol was reviewed and approved by the institutional review board at the Samsung Medical Center (registry no. SMC 2017-12-081). Informed consent was waived due to the retrospective nature of the study.

\section{Outcomes Measured}

\section{Primary Outcome: GMFM-66}

Assessment of GMFM-66 was performed by two pediatric physical therapists before and after the 8-week hippotherapy program. The change in GMFM-66 is a reliable tool for detecting changes in gross motor function in children with CP. ${ }^{17}$ GMFM- 66 consists of 66 items through Rasch's analysis, excluding 22 items with repeated difficulty levels.

\section{Secondary Outcome: GMFM-88}

The GMFM- 88 consists of 88 items in the following five dimensions: (A) lying and rolling; (B) sitting; (C) crawling and kneeling; (D) standing; and (E) walking, running, and jumping. $^{17}$

\section{Secondary Outcome: PBS}

The PBS is a modified version of the Berg's balance scale and used in children with spastic CP. The PBS consists of 14 items and evaluates functional balance in everyday tasks. The items assess the functional activities within the home, school, or community, including sitting balance, standing balance, sit to stand, stand to sit, transfers, stepping, reaching forward, reaching the floor, turning, and stepping on and off through an elevated surface. Each item is scored on a four-point scale. The validity and inter-/intrarater reliability of PBS have been demonstrated in children with $\mathrm{CP}^{20}$

\section{Statistical Analysis}

We regarded children with an increase in GMFM-66 of 2.0 points as good responders to hippotherapy as mentioned above. For sex, age, and distribution (only spastic type) subgroups, the Chi-square test was used to analyze the proportion of good responders. For CP type, Fisher's exact test was used to analyze the proportion of good responders. For GMFCS level, the linear-by-linear association method was used to analyze the proportion of good responders. The $t$ tests were used to compare GMFM-66, GMFM-88, and PBS changes according to sex, age, and distribution (only spastic type). For the CP type and GMFCS level, Kruskal-Wallis test (nonparametric method) was used. For GMFCS level, MannWhitney test was used as a posttest.

The variables used for univariate logistic regression were age, sex, distribution, CP type, GMFCS level, baseline GMFM $\mathrm{A} / \mathrm{B} / \mathrm{C} / \mathrm{D} / \mathrm{E}$, and baseline PBS. For analysis purposes, GMFCS levels were stratified into three groups, namely, levels I and II, III, and IV. The possibility of self-ambulation and the necessity of using walking aids are the most important factors in classifying children with $\mathrm{CP}$ according to their motor function. Baseline GMFM-66 and baseline GMFM-88 were strongly correlated with each other. Therefore, baseline GMFM-88 was excluded from the selection of variables.
Variables with $p$-values less than 0.2 in the univariate logistic regression analysis were selected for multivariate logistic regression analysis to identify the factors that affected the efficacy of hippotherapy. The significance level was set at $<0.05$. All analyses were performed with SPSS version 24.0 software (IBM Corp., Armonk, New York, U.S.A.).

\section{Results}

We enrolled 155 participants who met the inclusion and exclusion criteria. Nine children were excluded from the final analysis owing to frequent absences ( $>$ four times). Finally, the data of 146 participants were analyzed retrospectively. The attendance rate of the participants was $94.0 \pm 8.0 \%$.

The mean age of the participants was $5.78 \pm 1.72$ years. Of the 146 participants, 82 (56.2\%) were boys; 128 (87.7\%), 10 (6.8\%), and eight (5.5\%) participants were spastic, dyskinetic, and ataxic $\mathrm{CP}$, respectively. Of the 128 children with spastic CP, 12 had a unilateral distribution; 24 (16.4\%), 48 (32.9\%), 44 (30.1\%), and $30(20.5 \%)$ participants were GMFCS levels I and II, III and IV (- Table 1), respectively.

Seventy-one participants (48.6\%) were good responders to hippotherapy. There was no difference in the proportion of good responder in sex, age, CP type and distribution subgroups. However, as a result of linear-by-linear association analysis, we found that as the GMFCS level increased, the proportion of good responder decreased ( $\mathbf{- T a b l e ~} \mathbf{1}$ ).

GMFM-88 changes in children with unilateral CP were significantly greater than in those with bilateral $\mathrm{CP}$ $(p=0.001)$. There was no statistical difference of GMFM66, GMFM-88 and PBS changes according to CP types. There were significant differences in GMFM-66, GMFM-88, and PBS changes according to the GMFCS level. Results are described in detail in - Table 2.

Variables with $p$-values less than 0.2 in the univariate logistic regression analysis were: the GMFCS level; the baseline GMFM B, C, D, and E scores; and the baseline PBS score. In the multivariate logistic regression analysis, GMFCS level of I and II compared with IV ( $p=0.046)$ and III compared with IV $(p=0.045)$, baseline GMFM E score $(p=0.031)$, were the factors that had a positive influence on good response to hippotherapy. Baseline GMFM B score $(p=0.046)$ had a negative influence on good response to hippotherapy. Sex, age, СP type and distribution were not factors influencing gross motor outcome of hippotherapy according to our analysis (-Table $\mathbf{3}$ ).

\section{Discussion}

Here, we found that the children with CP, GMFCS levels I and II or III, with relatively poor postural control in sitting might have a greater chance to improve their GMFM-66 scores through hippotherapy. To our knowledge, this study is the first to analyze the factors that affect the therapeutic effect of hippotherapy. Conflicting evidence exists regarding the improvement of GMFM scores after hippotherapy. Despite this, many studies reported significant improvements: the most recent meta-analysis revealed an insignificant increase 
Table 1 Analysis of the ratios of good responders to hippotherapy among subgroups.

\begin{tabular}{|l|l|l|l|l|}
\hline Subgroups & $\begin{array}{l}\text { Total } \\
\boldsymbol{n}(\%)\end{array}$ & $\begin{array}{l}\text { Good responders } \\
\boldsymbol{n}(\%)\end{array}$ & $\begin{array}{l}\text { Poor responders } \\
\boldsymbol{n}(\%)\end{array}$ & $p$-Value \\
\hline Sex & & & & \\
\hline Boys & $82(56.2)$ & $39(47.6)$ & $43(52.4)$ & 0.770 \\
\hline Girls & $64(43.8)$ & $32(50.0)$ & $32(50.0)$ & \\
\hline Age (y) & & & & \\
\hline $3 \leq$ age $<6$ & $77(52.7)$ & $37(48.1)$ & $40(51.9)$ & 0.883 \\
\hline $6 \leq$ age $<11$ & $69(47.3)$ & $34(47.9)$ & $35(50.7)$ & \\
\hline CP type, $n$ (\%) & & & & 1.000 \\
\hline Spastic & $128(87.7)$ & $62(48.4)$ & $66(51.6)$ & 1.000 \\
\hline Dyskinetic & $10(6.8)$ & $5(50.0)$ & $5(50.0)$ & 1.000 \\
\hline Ataxic & $8(5.5)$ & $4(50.0)$ & $4(50.0)$ & \\
\hline Distribution (spastic type) & & & & 0.471 \\
\hline Unilateral & $12(9.4)$ & $7(58.3)$ & $5(41.7)$ & \\
\hline Bilateral & $116(90.6)$ & $55(47.4)$ & $61(52.6)$ & \\
\hline GMFCS level & & & & $<0.001$ \\
\hline I & $24(16.4)$ & $15(62.5)$ & $9(37.5)$ & \\
\hline II & $48(32.9)$ & $31(64.6)$ & $26(59.1)$ & \\
\hline III & $44(30.1)$ & $18(40.9)$ & $23(76.7)$ & \\
\hline IV & $30(20.5)$ & $7(23.3)$ & & \\
\hline
\end{tabular}

Abbreviations: CP, cerebral palsy; GMFCS, gross motor function classification system.

in GMFM score. ${ }^{16}$ Contributing to these contradictory results may be the limitations of small sample sizes, individual variability (gross motor functions, age, and $\mathrm{CP}$ types and distribution), types of intervention (hippotherapy vs. therapeutic horseback riding and private lesson vs. group lesson), and insufficient intervention duration. This study involves a relatively large number of subjects (146 participants with $\mathrm{CP})$. Furthermore, the intervention is relatively uniform over a sufficient period (single-center study for 8 weeks). As we also had observed that the degree of improvement in GMFM scores after hippotherapy had individual differences, we would like to analyze factors (individual variables) that affect the gross motor outcome measured using GMFM-66. As the minimal clinically important difference in GMFM-66 was reported to be 1.58 , we regarded the children with GMFM-66 scores increased by 2.0 points as good responders to hippotherapy. Moreover, we analyzed the factors that affected good responders.

Several studies have been conducted that investigate the factors are affecting the response of children with $\mathrm{CP}$ to physical therapy in a hospital setting. Chen et al reported that the PT efficacy of young ( $<3$ years old) children with CP was better and that the GMFM-66 score improved at 8 years of age. Furthermore, the improvement differed among the five GMFCS levels ( $p<0.001$ ), and GMFCS level II had a faster progression in Chen et al's study. ${ }^{20}$ Similar results were confirmed in another study on factors that affected the response to intensive therapy in children with $\mathrm{CP}$ or developmental delay. ${ }^{21}$ However, we could not find any additional effects of age on GMFM improvement after hippotherapy, which is not consistent with previous studies. ${ }^{20,21}$ This result is thought to be due to the fact that approximately half of the participants were aged 6 years or older who already reached the plateau of the GMFM-66 score. This can be paradoxically interpreted that hippotherapy can be an effective therapy for some school-aged children with little potential of further improvement in GMFM scores.

Like conventional PT, hippotherapy was more effective in the ambulatory group than in the nonambulatory group. The participants with GMFCS levels I and II and III were significantly more likely to be good responders than those with GMFCS level IV (-Table 3, odds ratio [OR] =6.83, 4.45). The most marked change in GMFM-88 was noted in GMFCS level III and the most marked change of PBS was noted in GMFCS level II. A recent study that used ICF-CY checklist confirmed that the effect of hippotherapy was distinct from GMFCS levels, and most improvements were present in children with GMFCS levels I-III. ${ }^{22}$

The GMFM-66 curves appear to reach plateaus by about age 7 years. Children, on average, reach approximately $90 \%$ of their motor function (as measured by the GMFM-66) by around age $\leq 5$ years, depending on their GMFCS level. Children with GMFCS levels IV and V are expected to achieve $90 \%$ of their potential GMFM score at the age of 3.5 and 2.7 years, respectively. ${ }^{23}$ Children with GMFCS levels IV and V exhibited significant limited motor function and potential to improve. ${ }^{24}$ However, this does not mean that hippotherapy should be performed only for children with GMFCS levels I 
174 Hippotherapy in Children with Cerebral Palsy Seung Mi et al.

Table 2 Changes of GMFM-66, GMFM-88, and PBS after hippotherapy

\begin{tabular}{|c|c|c|c|c|c|c|}
\hline \multirow[t]{2}{*}{ Subgroups } & \multicolumn{2}{|c|}{ GMFM-66 change } & \multicolumn{2}{|c|}{ GMFM-88 change } & \multicolumn{2}{|l|}{ PBS change } \\
\hline & Mean (SD) & $p$-Value & Mean (SD) & $p$-Value & Mean (SD) & $p$-Value \\
\hline \multicolumn{7}{|l|}{ Sex } \\
\hline Boys & $2.27(1.77)$ & 0.561 & $2.81(1.92)$ & 0.415 & $3.40(3.25)$ & 0.843 \\
\hline Girls & $2.45(2.10)$ & & $3.16(2.96)$ & & $3.30(3.13)$ & \\
\hline \multicolumn{7}{|l|}{ Age $(y)$} \\
\hline $3 \leq$ age $<6$ & $2.30(1.79)$ & 0.768 & $2.90(2.32)$ & 0.762 & $3.47(3.01)$ & 0.657 \\
\hline $6 \leq$ age $<11$ & $2.40(2.07)$ & & $3.02(2.56)$ & & $3.23(3.39)$ & \\
\hline CP type & & 0.818 & & 0.208 & & 0.523 \\
\hline Spastic & $2.32(1.94)$ & & $2.91(2.54)$ & & $3.29(3.24)$ & \\
\hline Dyskinetic & $2.39(1.50)$ & & $3.52(1.64)$ & & $4.30(3.10)$ & \\
\hline Ataxic & $2.78(2.23)$ & & $3.01(1.19)$ & & $3.25(2.98)$ & \\
\hline \multicolumn{7}{|l|}{ Distribution } \\
\hline Unilateral & $2.46(2.17)$ & 0.787 & $1.56(1.16)$ & 0.001 & $3.83(3.30)$ & 0.544 \\
\hline Bilateral & $2.30(1.92)$ & & $3.05(2.60)$ & & $3.23(3.25)$ & \\
\hline \multicolumn{7}{|l|}{ GMFCS level } \\
\hline 1 & $3.33(2.26)$ & $0.001^{\mathrm{a}}$ & $1.73(1.20)$ & $0.001^{c}$ & $2.88(2.13)$ & $<0.001^{d}$ \\
\hline II & $2.82(2.07)$ & $<0.001^{\mathrm{b}}$ & $2.86(2.16)$ & & $4.42(3.61)$ & \\
\hline III & $1.98(1.57)$ & & $3.76(2.95)$ & & $3.57(3.41)$ & \\
\hline IV & $1.36(1.17)$ & & $2.94(2.36)$ & & $1.73(2.00)$ & \\
\hline
\end{tabular}

Abbreviations: CP, cerebral palsy; GMFCS, gross motor function classification system; GMFM, gross motor function measure; PBS, pediatric balance scale; SD, standard deviation.

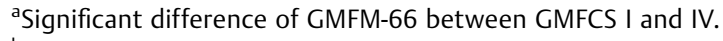

bSignificant difference of GMFM-66 between GMFCS II and IV.

'Significant difference of GMFM-88 between GMFCS I and III.

dSignificant difference of PBS between GMFCS II and IV.

and II, or III. The previous randomized controlled trial (RCT) study showed that the gross motor function of children with GMFCS level IV was also significantly improved as compared with that of the control group after hippotherapy. ${ }^{25} \mathrm{Hsieh}$ et al reported that the limitations of activities and participation domain of the ICF-CY checklist (d235-managing one's behavior, and d315-communicating with or receiving nonverbal messages) were reduced after hippotherapy in children with GMFCS levels IV and V. They thought that this improvement may have been due to an increased awareness of the child's ability to communicate and perform general tasks and respond to demands. The authors stated that hippotherapy may provide these children with a modifying activity that ensures their participation in building a relationship with a horse. ${ }^{22}$

The GMFM D and $\mathrm{E}$ areas have a decisive impact on the GMFM-66 score. All 13 GMFM-88 D items and all 24 GMFM-88 E items are included in GMFM-66. Therefore, high GMFM D and E scores can affect further improvement in GMFM-66 score. We found that baseline GMFM E score (walking, running, and jumping) was a positive predictive factor of hippotherapy. However, unexpectedly, we found that a lower B score (a low sitting function) predicts a better outcome of hippotherapy. During hippotherapy, children do various activities to improve postural control in the sitting position. Previous meta-analysis studies demonstrated that EAATs are indicated to improve postural control and balance in children with $\mathrm{CP} .{ }^{10}$ The present results and previous meta-analysis results suggest that hippotherapy is a context-focused therapy to improve postural control in sitting. Children with CP and GMFCS levels I and II or III who have relatively poor postural control in sitting might have a greater chance to improve their GMFM-66 scores through hippotherapy. This result also supports the recent study which suggests that hippotherapy shows distinct therapeutic strengths with regard to promoting upright stand and gait in children with cerebral palsy. ${ }^{26}$

We did not find any influence of $\mathrm{CP}$ type and distribution on the increase in GMFM-66 score after hippotherapy. Relatively fewer ataxic (5.5\%) and dyskinetic (6.8\%) CP cases than spastic cases were enrolled in this study. Spastic CP is the most common type of $\mathrm{CP}$, accounting for 72 to $91 \%$ of $\mathrm{CP}$ cases. ${ }^{27}$ Furthermore, children with dyskinetic $\mathrm{CP}$ were reported to have more severe cognitive and motor impairments than children with bilateral spastic $\mathrm{CP}^{28}$ Therefore, they were likely to have been excluded from the therapy according to our inclusion/ exclusion criteria. There is a big difference in gross motor function between the children with unilateral $\mathrm{CP}$ and those with bilateral CP; $98 \%$ of hemiplegia, $66.7 \%$ of diplegia, and only 
Table 3 Factors that influence the therapeutic effect of hippotherapy.

\begin{tabular}{|c|c|c|c|c|c|}
\hline \multicolumn{2}{|l|}{ Factors } & \multicolumn{2}{|c|}{ Univariate logistic analysis } & \multicolumn{2}{|c|}{ Multivariate logistic analysis } \\
\hline & & OR $(95 \% \mathrm{Cl})$ & $p$-Value & OR $(95 \% \mathrm{Cl})$ & $p$-Value \\
\hline \multirow[t]{2}{*}{ Sex } & Boys & Reference & - & - & - \\
\hline & Girls & $1.10(0.57-2.12)$ & 0.770 & - & - \\
\hline \multirow[t]{2}{*}{ Age (y) } & $3 \leq$ age $<6$ & Reference & - & - & - \\
\hline & $6 \leq$ age $<11$ & $1.05(0.55-2.01)$ & 0.883 & - & - \\
\hline \multirow[t]{2}{*}{ Distribution } & Unilateral & Reference & - & - & - \\
\hline & Bilateral & $0.65(0.20-2.16)$ & 0.485 & - & - \\
\hline \multirow[t]{3}{*}{ GMFCS level } & I or II & $5.81(2.20-5.38)$ & $<0.001$ & $6.83(1.03-45.09)$ & 0.046 \\
\hline & III & $2.28(0.81-6.42)$ & 0.121 & $4.45(1.03-19.16)$ & 0.045 \\
\hline & IV & Reference & - & Reference & - \\
\hline \multirow[t]{3}{*}{ CP type } & Spastic & Reference & - & - & - \\
\hline & Dyskinetic & $1.07(0.29-3.86)$ & 0.924 & - & - \\
\hline & Ataxic & $1.07(0.26-3.86)$ & 0.932 & - & - \\
\hline \multirow{6}{*}{$\begin{array}{l}\text { Baseline } \\
\text { gross motor }\end{array}$} & Baseline GMFM A & $0.93(0.69-1.25)$ & 0.626 & - & - \\
\hline & Baseline GMFM B & $1.04(0.99-1.09)$ & 0.124 & $0.93(0.87-0.999)$ & 0.046 \\
\hline & Baseline GMFM C & $1.06(1.02-1.11)$ & 0.006 & - & - \\
\hline & Baseline GMFM D & $1.05(1.02-1.08)$ & 0.001 & - & - \\
\hline & Baseline GMFM E & $1.04(1.02-1.05)$ & $<0.001$ & $1.05(1.01-1.11)$ & 0.031 \\
\hline & Baseline PBS & $1.04(1.02-1.06)$ & $<0.001$ & - & - \\
\hline
\end{tabular}

Abbreviations: Cl, confidence interval; CP, cerebral palsy; GMFCS, gross motor function classification system; GMFM, gross motor function measure; PBS, pediatric balance scale; OR, odds ratio.

$3.9 \%$ of quadriplegia were reported as GMFCS levels I-II. ${ }^{29}$ The greater change of GMFM-88 in unilateral CP might be attributed to the high percentage of GMFCS levels I and II in this group.

Children's participation in activities at home, school, and community is one of the most important outcomes of rehabilitation interventions, because it is fundamental to their health and development. Most traditional interventions for children with $\mathrm{CP}$ focus primarily on factors in the domain of body function and structure. EAATs seem to be attractive to all children with $\mathrm{CP}$ and their family members, as it is a fun sport that improves their body functions, activities, and participation. ${ }^{22}$ Emerging therapy interventions for children with physical disabilities suggest focusing changes in the environment and/or the activity demands (i.e., context-focused therapy) rather than on directing change to the child's abilities (i.e., child-focused therapy) as a useful approach to improve function and participation. ${ }^{30}$ Furthermore, the recently introduced treatment models influenced by the dynamic systems theory consider task or activity completion as the goal, with less emphasis on remediation or "normalization" of movement components. ${ }^{31}$ From this point of view, EAATs can be a context-focused, goal-based therapy for children with $\mathrm{CP}$. During hippotherapy, the rider must perform various activities and tasks on the horse in real-life environments outside the therapy gym (barn, arena, nature, etc.). Moreover, human-horse interaction is a powerful motivation for engaging children's participation in the therapy. ${ }^{32}$ Novak stressed the importance of "child-active approaches" where the child is actively practicing real-life tasks during intervention (usually in real-life environments) to gain or consolidate real-life skills that they want to learn. ${ }^{33}$

\section{Limitations}

This study has several limitations. First, this is a retrospective study without a control group. A prospective RCT should be conducted to confirm our results. Our results indicate that walking ability is a determinant factor influencing motor outcome of hippotherapy in children with CP. Therefore, in designing future studies, the GMFCS level of children should be considered as an inclusion/exclusion criterion. Hippotherapy is currently classified as a yellow-light intervention which had either lower-level evidence supporting their effectiveness or inconclusive evidence. Novak stated that "when yellow-light interventions are used, it is imperative that clinicians utilize a sufficiently sensitive outcome measure to confirm whether or not the intervention is working and if it is helping the child to achieve their family's goals." ${ }^{33}$ From this point of view, the Canadian occupational performance measure and goal attainment scaling (GAS) are recommended as outcome measures in EAATs or hippotherapy research. Both measures work well within a family-centered approach because they encourage family-led goal setting and facilitate individualization that is critical to heterogeneous conditions, such as CP. The therapeutic riding assessment of impact network proposed using GAS as a common outcome measure at four therapeutic riding 
centers since 2014. Further several previous RCTs on EAATs or hippotherapy examined mostly body structure and function, such as muscle asymmetry, spasticity, gait, gross motor function, and balance, using various laboratory and clinical measures, such as surface electromyography, ${ }^{34}$ modified Ashworth scale, ${ }^{35}$ GMFM, ${ }^{25,36}$ and PBS. ${ }^{25}$ Only two RCTs ${ }^{26,36}$ used the CP quality of life questionnaire for children, child health questionnaire, and the KIDSCREEN-27 that represent quality of life. When planning EAAT or hippotherapy clinical trials, we recommend standardized outcome measures that meet corresponding individual's goals based on the ICF model (body structure/function, activity, and participation). The complexity of EAATs or hippotherapy has an important influence on RCT design. The key issues to consider include the definition of each intervention and their components, the person providing the intervention (therapists, instructors, and side-walkers), and where and how the interventions will be standardized and monitored during the trial. Second, the proportion of children significantly differed with CP type. Supplementing the proportion of children with ataxic/dyskinetic $\mathrm{CP}$ and hemiplegic $\mathrm{CP}$ may enable further analysis. Third, factors related to the longterm effects of hippotherapy remain unknown. Furthermore, this retrospective study did not clarify the effects of the individual language ability, cognitive level, and attention on GMFM improvement after hippotherapy. Fourth, the examiners were not blind to the intervention and therefore, the postintervention ratings could have a positive bias.

\section{Conflict of Interest}

The authors have no conflicts of interest to disclose.

\section{Acknwoledgements}

This work was supported by Korea Institute of Planning and Evaluation for Technology in Food, Agriculture, Forestry (IPET) through Agri-Bio Industry Technology Development Program, funded by Ministry of Agriculture, Food and Rural Affairs (MAFRA) (316086-2) and Basic Science Research Program through the National Research Foundation of Korea funded by the Ministry of Education (NRF2017R1A2B4004615).

\section{References}

1 Ryan JM, Cassidy EE, Noorduyn SG, O'Connell NE. Exercise interventions for cerebral palsy. Cochrane Database Syst Rev 2017;6: CD011660

2 World Health Organization. International Classification of Functioning, Disability and Health: Children \& Youth Version. Geneva, Switzerland: WHO Publications; 2007

3 Damiano DL. Activity, activity, activity: rethinking our physical therapy approach to cerebral palsy. Phys Ther 2006;86(11): 1534-1540

4 Lee BH, Kim YM, Jeong GC. Mediating effects of the ICF domain of function and the gross motor function measure on the ICF domains of activity, and participation in children with cerebral palsy. J Phys Ther Sci 2015;27(10):3059-3062

5 Law M, King G, King S, et al. Patterns of participation in recreational and leisure activities among children with complex physical disabilities. Dev Med Child Neurol 2006;48(05):337-342
6 Carlon SL, Taylor NF, Dodd KJ, Shields N. Differences in habitual physical activity levels of young people with cerebral palsy and their typically developing peers: a systematic review. Disabil Rehabil 2013;35(08):647-655

7 Damiano DL. Rehabilitative therapies in cerebral palsy: the good, the not as good, and the possible. J Child Neurol 2009;24(09):1200-1204

8 Bain AM. Pony riding for the disabled. Physiotherapy 1965; 51:263-265

9 McGee MC, Reese NB. Immediate effects of a hippotherapy session on gait parameters in children with spastic cerebral palsy. Pediatr Phys Ther 2009;21(02):212-218

10 Zadnikar M, Kastrin A. Effects of hippotherapy and therapeutic horseback riding on postural control or balance in children with cerebral palsy: a meta-analysis. Dev Med Child Neurol 2011;53 (08):684-691

11 Lauruschkus K, Nordmark E, Hallström I. “It's fun, but ...” Children with cerebral palsy and their experiences of participation in physical activities. Disabil Rehabil 2015;37(04):283-289

12 Stergiou A, Tzoufi M, Ntzani E, Varvarousis D, Beris A, Ploumis A. Therapeutic effects of horseback riding interventions: a systematic review and meta-analysis. Am J Phys Med Rehabil 2017;96 (10):717-725

13 Kwon JY, Chang HJ, Lee JY, Ha Y, Lee PK, Kim YH. Effects of hippotherapy on gait parameters in children with bilateral spastic cerebral palsy. Arch Phys Med Rehabil 2011;92(05):774-779

14 Park ES, Rha DW, Shin JS, Kim S, Jung S. Effects of hippotherapy on gross motor function and functional performance of children with cerebral palsy. Yonsei Med J 2014;55(06):1736-1742

15 Whalen CN, Case-Smith J. Therapeutic effects of horseback riding therapy on gross motor function in children with cerebral palsy: a systematic review. Phys Occup Ther Pediatr 2012;32(03):229-242

16 Tseng SH, Chen HC, Tam KW. Systematic review and metaanalysis of the effect of equine assisted activities and therapies on gross motor outcome in children with cerebral palsy. Disabil Rehabil 2013;35(02):89-99

17 Russell DJ, Rosenbaum PL, Cadman DT, Gowland C, Hardy S, Jarvis $\mathrm{S}$. The gross motor function measure: a means to evaluate the effects of physical therapy. Dev Med Child Neurol 1989;31(03): 341-352

18 Wang HY, Yang YH. Evaluating the responsiveness of 2 versions of the gross motor function measure for children with cerebral palsy. Arch Phys Med Rehabil 2006;87(01):51-56

19 McGibbon NH, Andrade CK, Widener G, Cintas HL. Effect of an equine-movement therapy program on gait, energy expenditure, and motor function in children with spastic cerebral palsy: a pilot study. Dev Med Child Neurol 1998;40(11):754-762

20 Chen CL, Shen IH, Chen CY, Wu CY, Liu WY, Chung CY. Validity, responsiveness, minimal detectable change, and minimal clinically important change of Pediatric Balance Scale in children with cerebral palsy. Res Dev Disabil 2013;34(03):916-922

21 Hong BY, Jo L, Kim JS, Lim SH, Bae JM. Factors influencing the gross motor outcome of intensive therapy in children with cerebral palsy and developmental delay. J Korean Med Sci 2017;32(05):873-879

22 Hsieh YL, Yang CC, Sun SH, Chan SY, Wang TH, Luo HJ. Effects of hippotherapy on body functions, activities and participation in children with cerebral palsy based on ICF-CY assessments. Disabil Rehabil 2017;39(17):1703-1713

23 Rosenbaum PL, Walter SD, Hanna SE, et al. Prognosis for gross motor function in cerebral palsy: creation of motor development curves. JAMA 2002;288(11):1357-1363

24 Hanna SE, Rosenbaum PL, Bartlett DJ, et al. Stability and decline in gross motor function among children and youth with cerebral palsy aged 2 to 21 years. Dev Med Child Neurol 2009;51(04): 295-302

25 Kwon JY, Chang HJ, Yi SH, Lee JY, Shin HY, Kim YH. Effect of hippotherapy on gross motor function in children with cerebral palsy: a randomized controlled trial. J Altern Complement Med 2015;21(01):15-21 
26 Deutz U, Heussen N, Weigt-Usinger K, et al. Impact of hippotherapy on gross motor function and quality of life in children with bilateral cerebral palsy: a randomized open-label crossover study. Neuropediatrics 2018;49(03):185-192

27 Odding E, Roebroeck ME, Stam HJ. The epidemiology of cerebral palsy: incidence, impairments and risk factors. Disabil Rehabil 2006;28(04):183-191

28 Himmelmann K, McManus V, Hagberg G, Uvebrant P, KrägelohMann I, Cans C; SCPE collaboration. Dyskinetic cerebral palsy in Europe: trends in prevalence and severity. Arch Dis Child 2009;94 (12):921-926

29 Howard J, Soo B, Graham HK, et al. Cerebral palsy in Victoria: motor types, topography and gross motor function. J Paediatr Child Health 2005;41(9,10):479-483

30 Anaby D, Law M, Teplicky R, Turner L. Focusing on the environment to improve youth participation: experiences and perspectives of occupational therapists. Int J Environ Res Public Health 2015;12(10):13388-13398

31 Law MC, Darrah J, Pollock N, et al. Focus on function: a cluster, randomized controlled trial comparing child- versus context- focused intervention for young children with cerebral palsy. Dev Med Child Neurol 2011;53(07):621-629

32 Franki I, Desloovere K, De Cat J, et al. The evidence-base for basic physical therapy techniques targeting lower limb function in children with cerebral palsy: a systematic review using the International Classification of Functioning, Disability and Health as a conceptual framework. J Rehabil Med 2012;44(05):385-395

33 Novak I. Evidence-based diagnosis, health care, and rehabilitation for children with cerebral palsy. J Child Neurol 2014;29(08):1141-1156

34 Benda W, McGibbon NH, Grant KL. Improvements in muscle symmetry in children with cerebral palsy after equine-assisted therapy (hippotherapy). J Altern Complement Med 2003;9(06):817-825

35 Lucena-Antón D, Rosety-Rodríguez I, Moral-Munoz JA. Effects of a hippotherapy intervention on muscle spasticity in children with cerebral palsy: A randomized controlled trial. Complement Ther Clin Pract 2018;31:188-192

36 Davis E, Davies B, Wolfe R, et al. A randomized controlled trial of the impact of therapeutic horse riding on the quality of life, health, and function of children with cerebral palsy. Dev Med Child Neurol 2009;51(02):111-119, discussion 88 